\title{
Influence on the Phase Formation and Strength of Porcelain by Partial Substitution of Fly Ash Compositions
}

\author{
Nur Azureen Alwi Kutty ${ }^{1 *}$, Mohamad Zaky Noh ${ }^{1}$, Mohd Zul Hilmi Mayzan', Sani Garba Durumin Iya1 \\ ${ }^{1}$ Materials Physics Laboratory, Department of Physics and Chemistry, Faculty of Applied Science and Technology, Universiti Tun \\ Hussein Onn Malaysia, Pagoh Campus, 84600 Pagoh, Johor, Malaysia \\ *Corresponding authorE-mail: awin_alwi@yahoo.com
}

\begin{abstract}
This paper presents the study of the influence on the phase formation and strength of the porcelain by the partial substitution of fly ash. The fly ash was calcined at the temperature of $800{ }^{\circ} \mathrm{C}$ and partially substituted into feldspar. Each mixture were mixed and pressed into green pellets sintered at different sintering temperature $\left(1100-1300{ }^{\circ} \mathrm{C}\right)$ at the interval of $50{ }^{\circ} \mathrm{C}$ for 120 min. The compressive strength, crystalline phase and the microstructure of the porcelain were investigated. The optimum physical and mechanical properties were obtained at $5 \mathrm{wt} \%$ of fly ash porcelain sintered at $1250{ }^{\circ} \mathrm{C}$. The apparent porosity reaches a minimum value with $0.22 \%$ which is nearly to zero and obtained the highest compressive strength of $105.40 \mathrm{MPa}$. The XRD results reveal that the highest percentage of mullite was obtained at the substitution of $5 \mathrm{wt} \%$ of fly ash with $49.0 \%$. The glassy phase shows an increasing trend with dissolution of mullite content which affects the strength and microstructure of the porcelain.
\end{abstract}

Keywords: Fly Ash; Microstructure; Phases; Porcelain; Strength

\section{Introduction}

Porcelain is a traditional ceramic materials which also known as 'whitewares' ceramic due to its white color. Porcelain is systematically produced by three main raw materials of clay, feldspar and quartz with a ratio of 50:25:25 referred as triaxial porcelain. It is comprised of plastic materials, fluxing agent and inert materials as presented in Figure 1 [1]. Although it has been established since $20^{\text {th }}$ century, porcelain is still categorized as higher complexities ceramic in phase development [2]. Generally, quartz $\left(\mathrm{SiO}_{2}\right)$ and mullite $\left(3 \mathrm{Al}_{2} \mathrm{O}_{3} \cdot 2 \mathrm{SiO}_{2}\right)$ are the main crystalline phase in porcelain. Iqbal and Lee reported that the equilibrium relation between different phases of the raw material changes due to the vitrification process which required higher temperature thus lead to the development of crystalline phase in porcelain [3]. Literally, the compositional of raw materials of porcelain are widely presented in $\mathrm{K}_{2} \mathrm{O}$ $\mathrm{Al}_{2} \mathrm{O}_{3}-\mathrm{SiO}_{2}$ phase system $[2,3]$.

The plasticity characteristic in clay or well known in industry as plastic clay or ball clay helps in giving shape in the forming process [4]. The kaolinite $\mathrm{Al}_{2} \mathrm{Si}_{2} \mathrm{O}_{5}(\mathrm{OH})_{4}$ (clay mineral) contain of hydroxyl group dehydroxylated at $450 \sim 550{ }^{\circ} \mathrm{C}$ and transform into metakaolin, $2\left(\mathrm{Al}_{2} \mathrm{O}_{3} \cdot 2 \mathrm{SiO}_{2}\right)$ [3]. Above $900{ }^{\circ} \mathrm{C}$, the aluminosilicate spinel $\left(2 \mathrm{Al}_{2} \mathrm{O}_{3} \cdot 3 \mathrm{SiO}_{2}\right)$ phase form by the decompositions of metakaolin. Some of the researcher are reported it as the $\gamma-\mathrm{Al}_{2} \mathrm{O}_{3}$ phase [2]. The aluminosilicate phase gives rise to the primary mullite above the temperature of $900{ }^{\circ} \mathrm{C}$ which can be seen as the agglomerate of small $(<0.5 \mu \mathrm{m})$ mullite crystal [5]. There are two types of mullite which are primary mullite and secondary mullite [6]. The transformation of primary to secondary mullite forms through the reaction of clay relicts with feldspar melts at around $1200{ }^{\circ} \mathrm{C}$ and referred as elongated needle-shaped $(>1 \mu \mathrm{m})$ mullite crystal which is called as secondary mullite [5]. However, some of the researcher reported that all the primary mullite transformed to secondary mullite at around the sintering temperature of $1350-$ $1400{ }^{\circ} \mathrm{C}$ due to complete dissolution of quartz grains. This behaviour allows the formation of porcelain microstructure consisting of glass, mullite and quartz $[2,4]$.

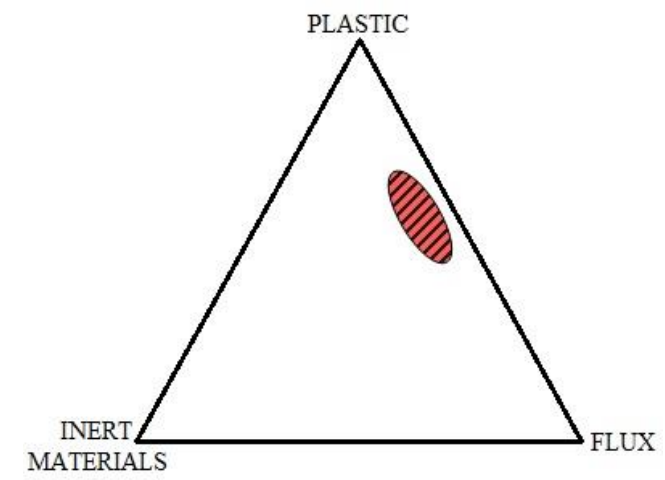

Fig. 1: Ternary diagram of compositional materials in porcelain

Dana and Das reported over the sintering temperature of $1300{ }^{\circ} \mathrm{C}$, the microcracks commonly occurred around quartz grain on the porcelain microstructure due to large thermal expansion coefficient mismatch between quartz and silicate glass matrix [7]. Generally, quartz (filler) is an inert material with high melting point $(<$ $1300{ }^{\circ} \mathrm{C}$ ) which could reduce the shrinkage and prevent the porcelain bodies to distort during firing process [8]. Meanwhile, feldspar as a flux consists of alkali and alkaline earth metal giving higher vitrification in porcelain. In addition, feldspar minerals also could influence the crystallization behaviour where it could improve the mechanical strength of the porcelain. In emphasizing the strength of the porcelain, several researchers used waste product as part of the raw materials of porcelain in order to improvise its 
quality. In fact, the waste materials influenced the crystalline phase behaviour of porcelain. In the present study, feldspar partially replaced by fly ash and sintered in various sintering temperature. The aim of this study is to investigate the phase changes and mechanical behaviour of the porcelain by the substitution of fly ash compositions according to the different sintering temperature.

\section{Experimental Procedure}

The fly ash was heated through calcination process at $800{ }^{\circ} \mathrm{C}$ for 3 $\mathrm{h}$ to remove the amount of excess carbon in fly ash and then, mixed with clay, quartz and feldspar for $12 \mathrm{~h}$ to obtain the homogeneous mixture for six different porcelain bodies (Table 1). Each mixture was uni-axially pressed into pellet under 3 tonnes pressure using hydraulic press machine (Carver 3851-0) and isostatically pressed afterwards at $100 \mathrm{MPa}$ for higher pressure compaction from all directions using cold isostatic pressing (CP360). All the compacted pellets were placed in the electrical furnace and sintered with a heating rate of $2{ }^{\circ} \mathrm{C} / \mathrm{min}$ in the temperature range of $1100-1300{ }^{\circ} \mathrm{C}$ for $120 \mathrm{~min}$. The percentage of shrinkage was measured by measuring the volume of pellets before and after sintering process and the apparent porosity was measured according to ASTM C373-88. The compressive strength was determined using universal testing machine (Testometric) as ASTM C773-88 The chemical analysis of the raw materials was characterized using X-ray Fluorescence (XRF). Characterization on the crystalline phase of the raw materials was carried out using X-ray Diffraction (Bruker D8 Advance) with $\mathrm{Cu} \mathrm{K} \alpha$ radiation and analyzed through X'Pert High Score Plus software (PANalytical). Scanning Electron Microscope (SEM) Hitachi-SU1510 was used to determine the microstructure of the samples.

Table 1: Sample compositions mixture (wt. \%)

\begin{tabular}{|l|c|c|c|c|}
\hline Sample & Clay & Quartz & Feldspar & Fly ash \\
\hline NP & 50 & 25 & 25 & 0 \\
\hline PFA5 & 50 & 25 & 20 & 5 \\
\hline PFA10 & 50 & 25 & 15 & 10 \\
\hline PFA15 & 50 & 25 & 10 & 15 \\
\hline PFA20 & 50 & 25 & 5 & 20 \\
\hline PFA25 & 50 & 25 & 0 & 25 \\
\hline
\end{tabular}

\section{Results and Discussions}

The chemical analysis of the raw materials used is presented in Table 2. Silica, $\mathrm{SiO}_{2}$ and alumina, $\mathrm{Al}_{2} \mathrm{O}_{3}$ are identified as the major compound in the raw materials of porcelain. Quartz shows the highest $\mathrm{SiO}_{2}$ content which is $96.95 \%$, followed by feldspar and clay with $72.59 \%$ and $56.31 \%$. Meanwhile, clay and feldspar contain of $39.20 \%$ and $19.28 \% \mathrm{Al}_{2} \mathrm{O}_{3}$ respectively. The chemical analysis results indicates higher $\mathrm{SiO}_{2}$ and $\mathrm{Al}_{2} \mathrm{O}_{3}$ content in fly ash which relevant as the raw materials of porcelain. The presence of $2.25 \%$ of alkali metals oxide $\left(\mathrm{K}_{2} \mathrm{O}\right.$ and $\left.\mathrm{Na}_{2} \mathrm{O}\right)$ and $1.89 \%$ of alkaline earth oxide $(\mathrm{CaO}$ and $\mathrm{MgO})$ in fly ash might influence the vitrification process in porcelain bodies.

Figure 2 shows the XRD pattern of the raw materials of porcelain and fly ash. The XRD pattern in Figure 2 (a) indicates clay contain of kaolinite and quartz whereas feldspar contain of albite, quartz, muscovite and microcline. Quartz mineral $\left(\mathrm{SiO}_{2}\right)$ is the major crystalline phase in quartz which is in line with the XRF results where $\mathrm{SiO}_{2}$ was observed as the highest oxide content in quartz. Figure 2 (b) indicates the presence of quartz, albite, mullite and cristobalite in fly ash. Quartz $\left(\mathrm{SiO}_{2}\right)$ and albite $\left(\mathrm{NaAlSi}_{3} \mathrm{O}_{8}\right)$ are observed as the major crystalline phase in fly ash which is $56.6 \%$ and $21.2 \%$ respectively, whereas mullite and cristobalite is $19.2 \%$ and $3 \%$. As can be observed from Figure 2 (b), the major crystalline phase of fly ash is similar to the feldspar minerals which probably relevant as the flux material. Albite is one of the feldspar mineral so-called as pure sodium Na-feldspar [10]. Tarhan reported that albite is completely dissolved above the sintering temperature of $1100{ }^{\circ} \mathrm{C}$ and helps in the formation of glassy phase in porcelain bodies [11].

Table 2: Chemical analysis of the raw materials (mass \%)

\begin{tabular}{|l|c|c|c|c|}
\hline Oxide content & Clay & Quartz & Feldspar & Fly ash \\
\hline $\mathrm{Na}_{2} \mathrm{O}$ & - & 0.07 & 2.13 & 0.36 \\
\hline $\mathrm{Al}_{2} \mathrm{O}_{3}$ & 39.20 & 2.53 & 19.28 & 26.20 \\
\hline $\mathrm{SiO}_{2}$ & 56.31 & 96.95 & 72.59 & 62.90 \\
\hline $\mathrm{P}_{2} \mathrm{O}_{5}$ & 0.03 & 0.01 & 0.39 & 0.46 \\
\hline $\mathrm{K}_{2} \mathrm{O}$ & 1.78 & 0.20 & 3.27 & 1.89 \\
\hline $\mathrm{CaO}$ & - & 0.04 & 1.47 & 1.32 \\
\hline $\mathrm{TiO}_{2}$ & 0.96 & 0.07 & 0.27 & 1.66 \\
\hline $\mathrm{Fe}_{2} \mathrm{O}_{3}$ & 1.13 & 0.07 & 0.35 & 3.57 \\
\hline $\mathrm{MgO}$ & 0.31 & - & 0.07 & 0.57 \\
\hline $\mathrm{L} . \mathrm{O} . \mathrm{I}$ & 0.27 & 0.05 & 0.17 & 1.06 \\
\hline
\end{tabular}
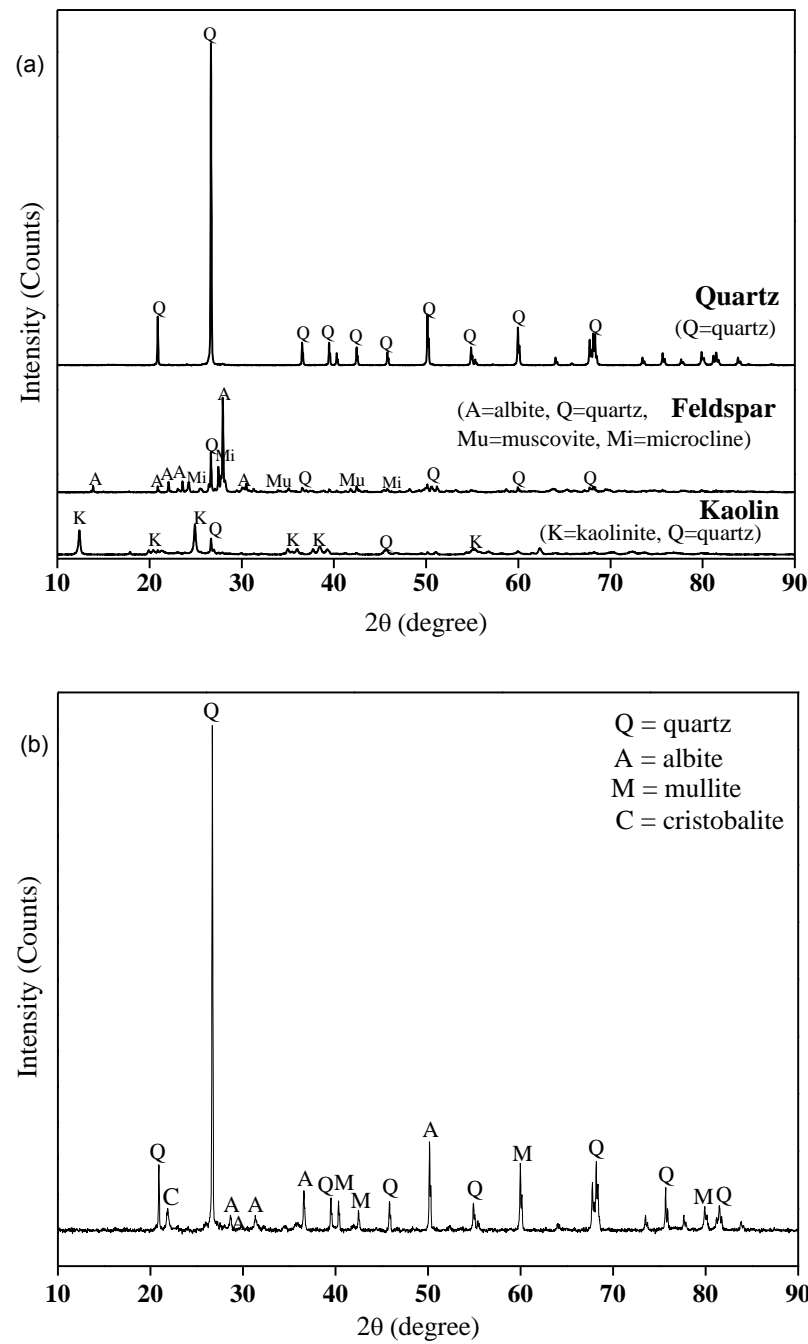

Fig. 2: (a) XRD pattern of the raw materials of porcelain, (b) XRD pattern of fly ash

The variations in the percentage of volume shrinkage are presented in Figure 3. From the figure, it may be observed that the percentage of shrinkage was increased with increasing in fly ash compositions at a sintering temperature of $1100^{\circ} \mathrm{C}$ up to $1200{ }^{\circ} \mathrm{C}$. There are no distinct changes on the percentage of shrinkage at lower temperature. However, the shrinkage shows decreasing trend over $1200{ }^{\circ} \mathrm{C}$ and abruptly decreased at the sintering temperature of $1300{ }^{\circ} \mathrm{C}$ probably due to higher quartz content originated from fly ash. The apparent porosity of the samples in various fly ash compositions and sintering temperature are presented in Figure 4. Higher percentage of apparent porosity presents at lower sintering temperature whereas the apparent porosity shows smaller percentage at higher temperature. It may be observed that 
the apparent porosity were decreased at $5 \mathrm{wt} \%$ of fly ash and then, increased evenly up to $20 \mathrm{wt} \%$ at the entire range of sintering temperature $\left(1100-1300{ }^{\circ} \mathrm{C}\right)$. However, over $1200^{\circ} \mathrm{C}$, the apparent porosity were decreased with increasing in fly ash compositions and reached almost zero value $(<0.1 \%)$ indicates almost densification achieved at this range of sintering temperature or probably due to over-firing behaviour. Same observation has been made by Das et al. where incorporation of fly ash with porcelain narrowed down the vitrification process [12]. Wang et al. also reported that fly ash porcelain matured earlier compared to the normal porcelain due to the presence of ferruginous and calcareous minerals from fly ash [13].

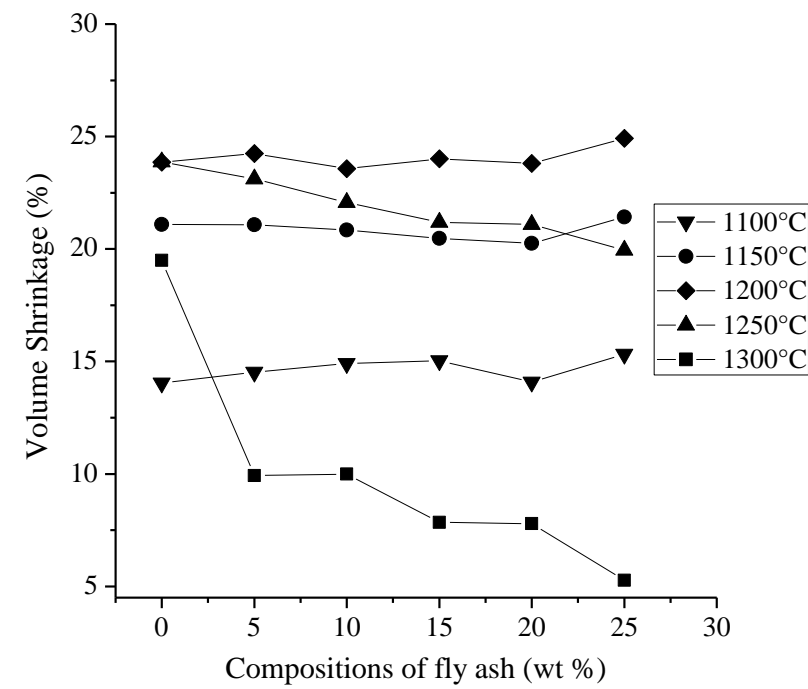

Fig. 3: Variations of the volume shrinkage in various compositions of fly ash and sintering temperature

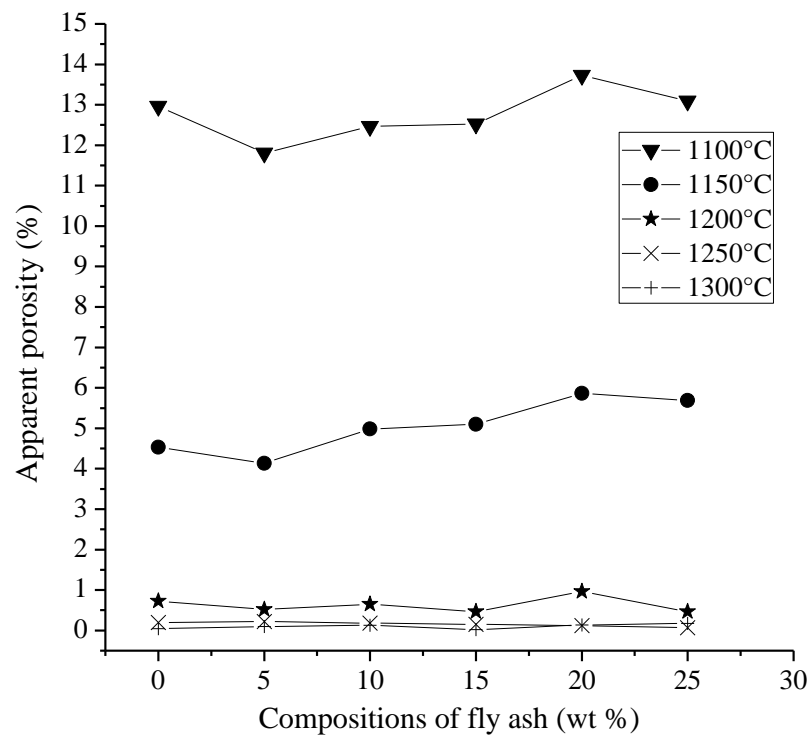

Fig. 4: Variations of the apparent porosity in various compositions of fly ash and sintering temperature

The compressive strength of the porcelain bodies are presented in Figure 5. From the figure, it was observed that the compressive strength was increased at $5 \mathrm{wt} \%$ fly ash and then, decreased up to $25 \mathrm{wt} \%$ fly ash at the sintering temperature range of 1100 $1250{ }^{\circ} \mathrm{C}$ due to the increasing in glassy phase rather than crystallizations of mullite which may be caused by the presence of alkali content in fly ash [14]. However, the compressive strength was decreased at $1300{ }^{\circ} \mathrm{C}$ with increasing in fly ash compositions. It might be related to the stress generated during the cooling process which caused by the larger difference of thermal expansion coefficient between quartz and silicate glassy matrix or probably due to in early stage of overfiring. The maximum strength of the porcelain bodies was achieved at 5 wt $\%$ of fly ash with $105.04 \mathrm{MPa}$ sintered at the sintering temperature of $1250{ }^{\circ} \mathrm{C}$ which observed as the optimum sintering temperature for the porcelain bodies.

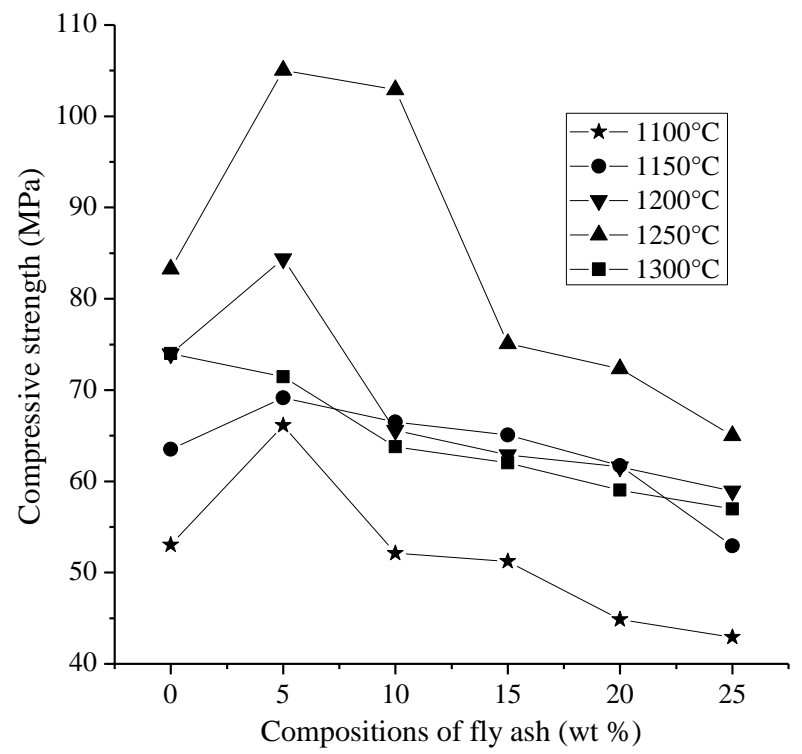

Fig. 5: Variations of the compressive strength of the samples in various compositions of fly ash and sintering temperature

The crystalline phase of the porcelain bodies sintered at $1250{ }^{\circ} \mathrm{C}$ was investigated by XRD presented in Figure 6. Meanwhile, the mass percentages of the phase content were quantitatively estimated by XRD presented in Figure 7. Quartz and mullite were identified as the major crystalline phase in normal porcelain and fly ash porcelain bodies. XRD indicates the presence of cordierite in 15 wt $\%$ of fly ash porcelain. It was observed that the normal porcelain (0 wt \% fly ash) contain of $54 \%$ of quartz and $46 \%$ of mullite. The highest percentage of mullite was observed at $5 \mathrm{wt} \%$ of fly ash which is $49 \%$ with decreasing in quartz phase to $51 \%$. Over $10 \mathrm{wt} \%$, quartz phase shows an increasing trend with decreasing in mullite content. However, $11 \%$ of cordierite $(\mathrm{Mg}, \mathrm{Fe})_{2} \mathrm{Al}\left(\mathrm{Al}_{3} \mathrm{Si} 5 \mathrm{O} 18\right)$ or known as iolite was indicates at 15 wt $\%$ of fly ash. The expansion of oxygen gas, $\mathrm{O}_{2}$ or known as "bloating" phenomenon are probably caused by the presence of cordierite where it is contain of $\mathrm{Fe}_{2} \mathrm{O}_{3}$ and transform into $\mathrm{Fe}_{3} \mathrm{O}_{4}$ at higher temperature which drastically decreased the densification and strength of the porcelain bodies [9].

The microstructure of 5, 15 and 20 wt $\%$ of fly ash are presented in Figure 8. From the figure, the presence of quartz and formation of mullite crystal was observed in Figure $8(\mathrm{a}, \mathrm{b}$ and $\mathrm{c})$. Growth of the cluster needles shaped crystals was observed where the crystals were transformed to the secondary mullite at higher temperature. The extensive micro-crack around the large quartz grains was observed in Figure 8 (a) and (b) due to quartz inversion taking place at the sintering temperature of $573{ }^{\circ} \mathrm{C}$ where $\alpha$-quartz transformed into $\beta$-quartz during cooling process and stress generated due to large difference in thermal expansion coefficients between quartz grains $\left(\alpha \sim 23 \times 10^{-6}{ }^{\circ} \mathrm{C}^{-1}\right)$ and glassy matrix $(\alpha \sim$ $3 \times 10^{-6}{ }^{\circ} \mathrm{C}^{-1}$ ) [5]. Excessive glassy phase content and higher formation of closed porosity are also clearly seen in Figure 8 (c) which affects the microstructure in porcelain bodies. Similar observation was made by Luo et al. where dissolutions of mullite increasing the glassy phase content leading to decrease in strength of the samples [15]. 


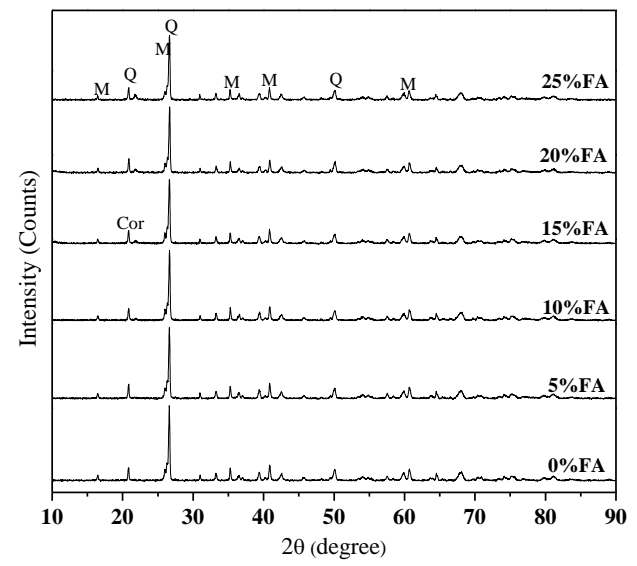

Fig. 6: XRD patterns of fly ash porcelain sintered at $1250{ }^{\circ} \mathrm{C}(\mathrm{M}=$ mullite, $\mathrm{Q}=$ quartz, Cor $=$ cordierite $)$

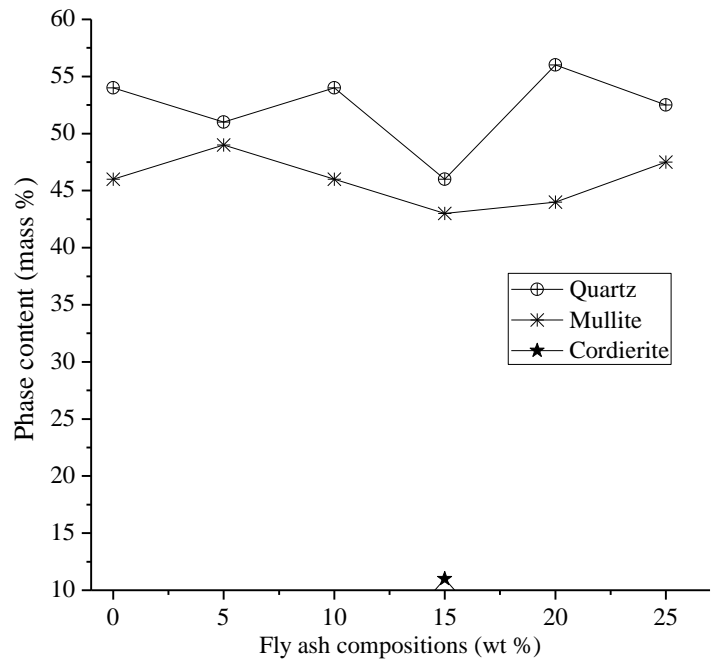

Fig. 7: Variations of phase content of fly ash porcelain bodies sintered at the sintering temperature of $1250{ }^{\circ} \mathrm{C}$

(a)

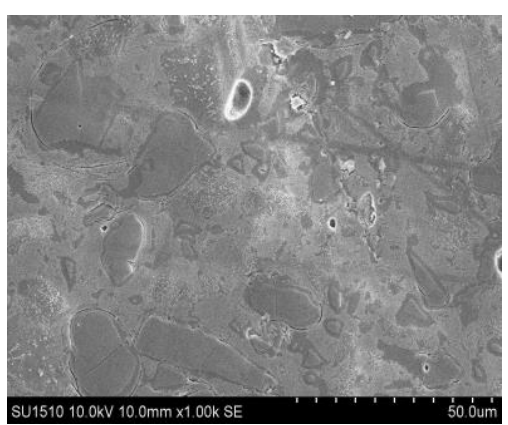

(b)

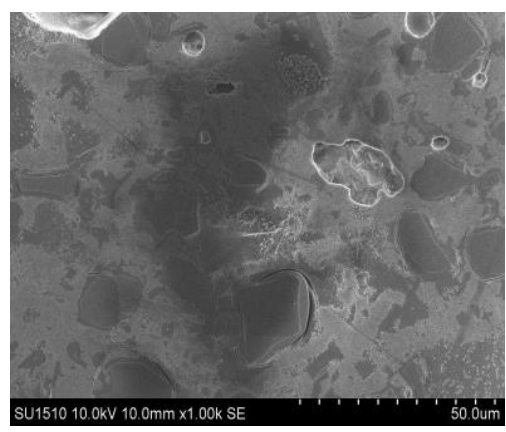

(c)

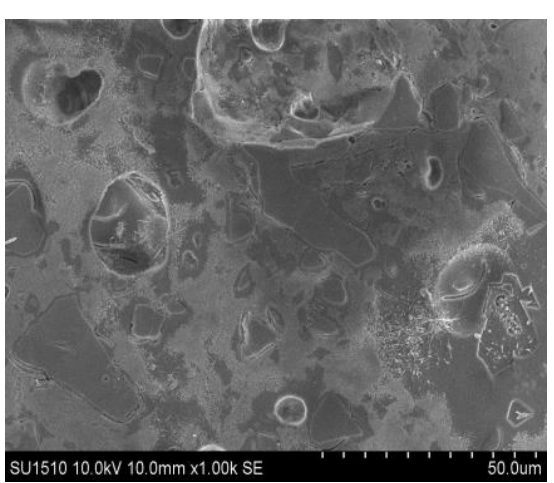

Fig. 8: SEM photomicrograph of fly ash porcelain bodies sintered at $1250{ }^{\circ} \mathrm{C}$; (a) PFA5, (b) PFA15, (c) PFA25

\section{Conclusions}

Partial substitutions of fly ash on feldspar enhanced the strength and densification of the porcelain. A mixture of $50 \mathrm{wt} \%$ of clay, 25 wt $\%$ of quartz, 20 wt $\%$ of feldspar and 5 wt $\%$ of fly ash was identified as the relevant compositions for porcelain sintered at a sintering temperature of $1250{ }^{\circ} \mathrm{C}$. The maximum compressive strength achieved at this composition with $105.04 \mathrm{MPa}$ compared to the normal porcelain with $83.28 \mathrm{MPa}$. The obtained apparent porosity reach nearly to zero value $(<0.1 \%)$ achieving the densification on the microstructure of the porcelain bodies. Mullite and quartz observed as the major crystalline phase in normal porcelain and fly ash porcelain. However, intense interlocking of fine mullite needles in glassy phase matrix observed at $5 \mathrm{wt} \%$ of fly ash contributed in achieving higher strength in porcelain. Beyond this composition, the glassy phase increased with dissolution of mullite affects the microstructure, thus decreased the densification of porcelain.

\section{Acknowledgement}

The authors would like to acknowledge the financial support from Universiti Tun Hussein Onn Malaysia (GPPS Grant: Vot U756). We also would like to thank Mr. Kamarul Affendi Bin Hamdan, Mr. Shahrul Mahadi bin Samsudin, Mr. Hasrul bin Ismail, Mr. Mohd Tarmizi bin Nasir, Mr. Anuar bin Ismail and Mr. Mohd Bahtiar bin Mohd Basri for the technical supports.

\section{References}

[1] Acchar W \& Dultra EJV (2015), Ceramic materials from coffee bagasse ash waste, Springer, 23-30.

[2] Carty WM \& Senapati U, "Porcelain-raw materials, processing, phase evolution, and mechanical behavior", J. Am. Ceram. Soc., Vol. 81, No. 1, (1998), pp. 3-20.

[3] Iqbal Y \& Lee WE, "Microstructural evolution in triaxial porcelain”, J. Am. Ceram. Soc., Vol. 83, No. 189015, (2000), pp. 31213127.

[4] Kingery WD, Bowen HK \& Uhlmann DR, Introduction to ceramics, Wiley, (1976), pp. 3-6.

[5] Martín-Márquez J, Rincón JM \& Romero M, "Mullite development on firing in porcelain stoneware bodies," J. Eur. Ceram. Soc., Vol. 30, No. 7, (2010), pp. 1599-1607.

[6] Duval DJ, Risbud SH \& Shackelford JF, Mullite, Springer, (2008), pp: 27-39.

[7] Dana K \& Das SK, "Partial substitution of feldspar by B.F. slag in triaxial porcelain: Phase and microstructural evolution", J. Eur. Ceram. Soc., Vol. 24, No. 15-16, (2004), pp. 3833-3839.

[8] Martín-Márquez J, Rincón JM \& Romero M, "Effect of firing temperature on sintering of porcelain stoneware tiles," Ceram. Int., Vol. 34, No. 8, (2008), pp. 1867-1873.

[9] Mukhopadhyay TK, Ghosh S, Ghosh J, Ghatak S \& Maiti HS, "Effect of fly ash on the physico-chemical and mechanical properties 
of a porcelain composition", Ceram. Int., Vol. 36, No. 3, (2010), pp. 1055-1062.

[10] Sokolár R \& Šveda M, "The use of zeolite as fluxing agent for whitewares", Procedia Eng., Vol. 151, (2016), pp. 229-235.

[11] Tarhan B, Tarhan M \& Aydin T, "Reusing sanitaryware waste products in glazed porcelain tile production", Ceram. Int., Vol. 43, No. 3, (2017), pp. 3107-3112.

[12] Das SK, Pal M, Ghosh J, Pathi KV \& Mondal S, "The effect of basic oxygen furnace slag and fly ash additions in triaxial porcelain composition: Phase and micro structural evolution", Trans. Indian Inst. Met., Vol. 66, No. 3, (2013), pp. 213-220.

[13] Wang H, Zhu M, Sun Y, Ji R, Liu L \& Wang X, "Synthesis of a ceramic tile base based on high-alumina fly ash," Constr. Build. Mater., Vol. 155, (2017), pp. 930-938.

[14] Dana K, Dey J \& Das SK, "Synergistic effect of fly ash and blast furnace slag on the mechanical strength of traditional porcelain tiles", Ceram. Int., Vol. 31, No. 1, (2005), pp. 147-152.

[15] Luo Y, Zheng S, Ma S, Liu C \& Wang X, "Ceramic tiles derived from coal fly ash: Preparation and mechanical characterization", Ceram. Int., Vol. 43, No. 15, (2017), pp. 11953-11966. 